\title{
Etnografiando la trama burocrática del "imaginado" posconflicto colombiano
}

\author{
Jefferson Jaramillo-Marín* \\ Pontificia Universidad Javeriana (Bogotá, Colombia)
}

Buchely, Lina (2020). El Estado de la Paz. Burocracias, memoria y afecto en el posconflicto colombiano. Bogotá/Cali: Tirant lo Blanch/Editorial Universidad Icesi, 180 págs.

El libro El Estado de la Paz. Burocracias, memoriay afecto en el posconflicto colombiano de Lina Buchely, profesora vinculada al departamento de Estudios Jurídicos de la Universidad Icesi, compendia en cinco capítulos un denso ejercicio reflexivo "sobre las formas de construir la paz institucional en Colombia" (15). Para ello, la profesora Buchely aborda cuatro grandes temas de análisis: "las nociones emergentes de ciudadanía" (21-42), "los nuevos y viejos retos de la administración pública en el escenario del posconflicto" (43-86), "la memoria como máquina" (87-146) y "las resistencias femeninas" (147-169).

El libro ofrece, a lo largo de sus 180 páginas, al menos tres perspectivas teóricas que van dialogando entre sí: la antropología política, la etnografía jurídica y la geografía legal. Estos tres armazones teóricos, con sus correspondientes basamentos conceptuales, le sirven a la autora para entender el "funcionamiento de los entramados burocráticos e institucionales que atienden a los reclamos de las víctimas" (17), pero sobre todo para poner en evidencia en qué medida "el poder de la trama burocrática trasciende las fronteras físicas de los procesos y coloniza la vida", y, por

\footnotetext{
* Doctor en Investigación en Ciencias Sociales de la Facultad Latinoamericana de Ciencias Sociales (México). Profesor Titular del Departamento de Sociología, Pontificia Universidad Javeriana (Colombia). Correo electrónico: jefferson. jaramillo@javeriana.edu.co ORCID: http://orcid.org/oooo-ooo2-oo16-7631
} 
tanto, desentrañar el sentido de una "burocracia que irradia tecnicismos e instituye procesos, con lo cual termina por crear la misma realidad que regula" (110).

Dos características del libro son el enmallado bibliográfico que lo recubre y el adobado etnográfico con el que condimenta su análisis. Con respecto a lo primero, la autora acude en auxilio de renombrados de la antropología política, la etnografía estatal y la sociología político-jurídica, esenciales siempre que se quiere volver sobre "el estado ${ }^{1}$ realmente existente en el país", como gusta de afirmar el historiador y politólogo Fernán González. Me refiero con ello a autores como Philip Abrams, Akhill Gupta, Partha Chatterjee, Jean Comaroff, John Comaroff, James Ferguson, Timothy Mitchell, Fernando Escalante, Javier Auyero y Michael Taussig, entre otros; la autora avanza, además, en la conversación con "noveles" estudiosos colombianos de las burocracias locales y las prácticas cotidianas estatales que despliegan en su ejercicio los funcionarios de lo transicional; me refiero con ello a autores/as como Juan Felipe García Arboleda, Juan Pablo Vera Lugo, Inés Cristina Jaramillo, Ángela Rivas, Gabriela Recalde, Juana Dávila, Everaldo Lamprea o Sandra Patricia Martínez, solo por mencionar algunos.

Frente al adobado etnográfico es necesario aclarar que deriva de la experiencia de la profesora Buchely, según sus propias palabras, "como investigadora vinculada [desde la Universidad Icesi] al Grupo Regional de Memoria Histórica, especialmente, en la reconstrucción de esta experiencia a la luz de la lectura de las emociones y la política desde la antropología del estado" (13). Empero, este libro, si se quiere aprovechar aún más su lectura, hay que ubicarlo dentro del trabajo multidisciplinario de varios años que ha venido co-liderando la Universidad Icesi-a través del Centro de Estudios Afrodiaspóricos- en Bellavista (Chocó), y que arroja ya varios frutos con otras publicaciones significativas de otros colegas de la autora, que deberían ser objeto de análisis específicos por su valor agregado a la discusión². Esta experiencia apalancada por Icesi ha tenido como objetivo contribuir al análisis cultural y político de los procesos de construcción de memoria, a propósito de un evento tristemente célebre para la región y el país: la masacre del 2 de mayo de 2002 o masacre de Bojayá.

En medio de tan prolífica y desigual literatura sobre el "imaginado" posconflicto colombiano, pero también sobre un contexto regional/local (el medio Atrato-Bojayá) donde se ha venido tejiendo un vasto trabajo intelectual desde entidades oficiales como el Centro Nacional de Memoria Histórica (CNMH) la Defensoría del Pue-

1. Aunque habitualmente esta palabra se escribe con E mayúscula, hacerlo con minúscula quiere destacar la necesidad de discutir, descentrar y desmitificar el lugar de predomino del estado (nota del autor).

2. Me refiero, entre otros, al trabajo de Vergara (2014; 2018), Cagüeñas (2019) y Cagüeñas, Galindo y Rasmussen (2020). 
blo, e instituciones académicas como la Universidad de Antioquia, la Universidad Nacional de Colombia o la Fundación Universitaria Claretiana, así como por muy variados/as investigadores/as ${ }^{3}$ y organizaciones defensoras de derechos humanos ${ }^{4}$, bien vale preguntarse en esta reseña: a. ¿por qué resulta significativo este texto y qué tanto aporta al campo de análisis? b. ¿ Dónde estarían algunas líneas o ejes por profundizar a partir del trabajo de la profesora Buchely?

En relación con la primera pregunta, este texto resulta significativo al menos por tres razones. En primer lugar, realiza al mismo tiempo un esfuerzo etnográfico sencillo y denso, en el que se propende por develar cómo opera la construcción de paz institucional hoy en el país y cuál es el estado in situ que apalanca la paz neoliberal elogiada en su momento, pero en significativa crisis hoy. Retomando las palabras de la autora que emergen desde las páginas iniciales, pero las cuales va desagregando a lo largo de los cinco capítulos, el interés básico de la investigación está en comprender "cómo se construye una particular forma de estado para el posconflicto, donde funcionarios y funcionarias van desplegando los guiones neoliberales del adelgazamiento del estado, a la vez que están preocupados por ser empáticos y afectivos con las víctimas a través de prácticas de gestión emocional, no material, de las vidas, los territorios y [los futuros de ellas]" (16).

En segundo lugar, hay un tejido analítico sugerente para pensar la memoria como dispositivo, como máquina. Deslindándose críticamente de los relatos teóricos que la ubican como "voz subalterna" o como "práctica de resistencia"-sin desconocer el valor de esto-, la autora va detallando con finas viñetas etnográficas cómo la memoria se inserta o "mora" en un entramado de gubernamentalidad complejo, donde "las burocracias de la memoria" se encargan de accionar y cotidianizar un "aparato público blando" que opera con "controles indirectos, trámites sinuosos, presencias opacas y afectivas que 'están ahí' pese a que no pueden hacer mucho" (p. 111). Burocracias que terminan siendo, como lo describe la autora en los capítulos tres y cuatro, parte de la "domesticación de la memoria", pero también de "la domesticación de la reparación y la no repetición [las fórmulas mágicas de la narrativa transicional que] colonizan los escenarios de las víctimas a través de metáforas y acciones tecnocientíficas, como talleres, capacitaciones, cartulinas, donde estas si bien enuncian su dolor -así sea en canciones [cómo es el caso de las cantadoras de Pogue]- siguen a la espera de sus derechos sociales y políticos" (145).

3. Solo por mencionar algunos de los trabajos académicos más representativos, y a riesgo de dejar muchos por fuera, tenemos a: Bello, Cardinal, Millán, Pulido y Rojas (2005); Castro y Erazo (2019); Giraldo (2020); Grupo de Memoria Histórica (GMH) y Comisión Nacional de Reparación y Reconciliación (CNRR) (2010); Millán (2009); Orjuela (2020); Quiceno (2015); Quiceno, Ochoa y Villamizar (2017).

4. Por ejemplo, el trabajo de la Comisión de Vida, Justicia y Paz de la Diócesis de Quibdó. 
En tercer lugar, el texto proporciona pistas sugerentes para pensar la "construcción de la subpolítica femenina como un contrapoder en los escenarios de posconflicto" (147). Lo importante aquí es que la autora no se queda solo en enunciar con grandilocuencia el "carácter resistente del subalterno", sino que va describiendo la complejidad de lo que significa hacer parte de espacios de contrapoder "sutiles", considerados por muchos como "tejidos livianos aparentemente superficiales", pero que devienen en territorios trinchera para construir consensos, confianzas requeridas para la acción colectiva, la acción jurídica, la acción política, como puede ser el juego del bingo, donde "juego, cuidado y ocio se vinculan de manera robusta para producir una sola voz: la voz de las víctimas de Bojayá, que es la voz de sus mujeres” (151). Esta subpolítica o infrapolítica está recubierta, por supuesto, de otros espacios y voces en el capítulo quinto del texto, como pueden ser el barrio, el cuerpo, la casa, la escuela, donde "las víctimas del pacífico resisten, subvierten, burlan, en ocasiones, lo que las oprime" (169), y que les permiten a ellas "tomarse y resignificar" el estado de la paz, del imaginado posconflicto.

Para finalizar esta reseña, no sin antes invitando a los lectores o lectoras a trasegar un texto que puede leerse de corrido sin perder el interés, me atrevo a sugerir dos ejes a profundizar y a "densificar" en posteriores trabajos, los cuales derivan de mi lectura sobre la apuesta conceptual y empírica de la profesora Buchely en este texto. El primero tiene que ver con una pista sugerida de pasada en la página 124, relacionada con la necesidad de etnografiar el estado en su "escala de grises", sin quedarnos únicamente con la dicotomía cerrada entre "ausencias y presencias" (124). Aquí creo que este llamado es a superar una vez más la vieja tesis de las "ausencias estatales" que tanta carrera hizo en el país, pero también a abrir a la discusión crítica la importante tesis aún vigente de Fernán González (2015) y el equipo de trabajo que él ha coliderado sobre la presencia diferenciada del Estado en el espacio y el tiempo. El segundo está relacionado con seguir etnografiando localmente los "guiones del estado de la paz", no solo el de la memoria, como hace la autora, sino también los de la reconciliación, el perdón, la convivencia, la paz territorial, las iniciativas de paz. Estos guiones domesticados y mistificados en muchos escenarios, por académicos y funcionarios, pueden decirnos mucho más del estado realmente existente, de sus efectos, de sus maneras de normalizarse o incrustarse en las vidas, en los relatos y en las prácticas. Estudiar más estos guiones también permitiría comprender las viejas tensiones del estado como "utopía imaginaria y como realidad compleja que involucra estrategias de fuga y evasión", tensiones que hace algunos años nos invitara a desentrañar el recientemente fallecido antropólogo y anarquista David Graber en un vibrante texto que cada vez gana más actualidad: Fragmentos de antropología anarquista (2011). 


\section{Referencias}

Bello, Martha N.; Cardinal, Elena; Millán, Constanza; Pulido, Belky; Rojas, Raquel (2005). Bojayá, memoria y río: violencia política, daño y reparación. Bogotá: Universidad Nacional de Colombia.

Cagüeñas, Diego. (2019). Historia como fantología: vida onírica, cantos mortuorios y el deber para con los espectros en Bojayá, Chocó. Philosophical Readings, 11(3), 176-182. https://doi. org/10.5281/zenodo.3560367

Cagüeñas, Diego; Galindo-Orrego, María Isabel; Rasmussen, Sabina. (2020). El Atrato y sus guardianes: imaginación ecopolítica para hilar nuevos derechos. Revista Colombiana de Antropología, 56(2), 169-196. https://doi.org/10.22380/2539472X.638

Castro, Ximena; Erazo, Cristian (2019). Las víctimas o las nuevas subjetividades políticas: pesquisa sobre la identidad de víctima en Bojayá (Chocó), Colombia. Athenea Digital,19(1), 1-22. https://doi.org/10.5565/rev/athenea.2271

Giraldo, Francisco (2020). La masacre de Bojayá: usos políticos de un recuerdo violento. Anuario Colombiano de Historia Socialy de la Cultura, 47(2), 43-84. https://doi.org/10.15446/ achsc.v47n2.86136

GMH; CNRR (2010). Bojayá. La guerra sin límites. Bogotá: Taurus.

González, Fernán (2015). Poder y violencia en Colombia. Bogotá: Cinep/Colciencias.

Graeber, David (2011). Fragmentos de antropología anarquista. Barcelona: Virus Editorial.

Millán, Constanza (2009). Ya no llega el limbo porque la gente bailando está. Prácticas de memoria en Bojayá-Chocó [Tesis de maestría]. Universidad Nacional de Colombia, Bogotá, Colombia.

Orjuela, Diana. (2020). ¿Qué hacemos con tanto muerto junto? Tratar la muerte violenta y masiva en el Medio Atrato. Revista Colombiana de Antropología, 56(2), 51-78. https://doi. org/10.22380/2539472X.648

Quiceno, Natalia (2015). Vivir sabroso. Poéticas de las luchasy movimientos afroatrateños. Bojayá, Chocó [Tesis de doctorado]. Universidade Federal do Rio de Janeiro, Río de Janeiro, Brasil.

Quiceno, Natalia; Ochoa, María; Villamizar, Adriana (2017). La política del canto y el poder de las alabaoras de Pogue (Bojayá, Chocó). Estudios Políticos, 51, 175-195. https://doi. org/10.17533/udea.espo.n51a09

Vergara-Figueroa, Aurora (2014). Ripped from the Land, Shipped Away and Reborn: Unthinking the Conceptual and Socio-Geo-Historical Dimensions of the Massacre of Bellavista [Tesis de maestría]. University of Massachusetts, Amherst, Estados Unidos.

Vergara, Aurora (2018). Afrodescendant Resistance to Deracination in Colombia. Massacre at Bellavista-Bojayá-Chocó. Suiza: Palgrave MacMillan. 